\title{
USAGE OF DIGITAL COMMUNICATIONS TOOLS WITHIN ORGANIC FARMING INDUSTRY IN LATVIA
}

\author{
Denis Vasiliev \\ Turiba University, Latvia \\ denisksil@gmail.com
}

\begin{abstract}
Organic farming plays a significant role in sustainable development of the EU and has a significant positive contribution to economy and environment of the region. Latvia is among leading countries of the EU with a substantial land area under organic farming. Globalization and local competitive rivalry make it increasingly hard for smallholder farmers to succeed. Digital marketing tools and e-commerce provide significant opportunities for building a sustainable competitive advantage. Usage of such tools is particularly promising for organic farming industry in Latvia, given high level of internet penetration in the country. However, it is important to understand to what extent organic farmers and professional organizations within the industry take advantage of the digital communications tools. In the present study the author examines usage of e-commerce and digital marketing tools among Latvian organic farmers and non-governmental organizations (NGOs) operating within the sector by comparing the situation with the usage of online tools in Western European countries and the US. Findings of the present study suggest that there is a scope for increasing effectiveness of e-commerce and digital marketing among organic farmers and NGOs. Increasing uptake of digital strategies among Latvian organic farmers and professional NGOs is likely to create a sustainable competitive advantage of the industry, not only at a local market, but also in the international context. This would have positive impacts on national economy and natural environment, as well as the health of the citizens. It is, therefore, recommended to promote usage of the digital tools within the industry by implementation of educational programmes at a national scale.
\end{abstract}

Keywords: e-agriculture, sustainable development, information technologies, competitive advantage, ecommerce.

\section{Introduction}

Recent UN Report [1] suggests that the world has failed to meet the Global Biodiversity Targets. In Europe agricultural intensification was found to be among the main drivers of ecosystem degradation and species extinctions [2]. Given the fact that soil fertility, pollination and pest control depend on biodiversity, loss of ecosystem integrity can potentially undermine human food security in the nearest future [3]. Risks to food security may be minimized through widespread uptake of sustainable agricultural practices across Europe. In attempt to address this issue, the EU biodiversity strategy includes recommendations for farmers to move from conventional agriculture to organic farming or other sustainable approaches [4]. However, farmers operating in organic farming industry often suffer from competition with the conventional farmers, due to limited market access and economies of scale [5]. The UN [6] recommends application of e-agriculture tools in order to facilitate sustainable development. The tools that could be particularly relevant for increasing competitive advantage of the farmers operating in organic industry include e-commerce and digital marketing. Application of ecommerce could allow organic farmers to sell their products directly to environmentally conscious customers and reduce the need for partnerships with retail chains. At the same time digital marketing could increase awareness of the benefits of organic food among potential consumers and help building the demand for sustainable agricultural products.

Latvia is among leading countries in the EU in terms of internet connection and coverage, providing internet access to more than $80 \%$ of households. This provides a great opportunity for local organic farmers to harness digital communications tools. Thus, local farmers could potentially benefit from utilization of e-commerce and digital marketing. Moreover, Latvia is among leading countries of the EU in terms of proportion of organic farmland area [7]. However, ongoing farmland consolidation and land abandonment in Latvia, signal that smallholder organic farmers may experience competitive disadvantage vis a vis conventional operators and foreign competitors [8]. It is, therefore, important to understand, whether the reason of organic smallholder decline may be associated with lack of digital tool utilization. Thus, in the aim of this research is to identify whether organic farmers in Latvia utilise digital communications tools and whether there is a scope for improvement in this area. Findings of the present study may help increase competitiveness of organic famers in Latvia, thereby positively contributing to overall sustainable development of the country and to local economy. The findings may also provide indications for application of information technology engineering in organic farming. 


\section{Materials and methods}

In order to evaluate usage of e-commerce tools among Latvian organic farmers a sample of 100 farms was selected using the random sampling method. A random number table from a book "Reproduced from Million Random Digits" by RAND corporation [9] was used. Data were selected from the Latvian Agricultural Data Centre database of certified organic farmers [10], containing 3264 total records. Only farms that are registered as companies were selected, private individuals were not included in a sample. Google search was undertaken on farms from the sample. Findings were summarised in an Excel spreadsheet that contained the following columns: name of the farm, its location, product category, website address, if present, presence of web-store on the website, social media page address, if present, purpose of the social media page (commercial or not). Proportions of farmers that had web-sites, web-stores and/or were present on social media were estimated. Farmers were categorized based on product categories (i.e., growers, livestock producers, poultry and egg producers, beekeepers) and geographical location. Most popular social media platforms were identified.

For the purpose of evaluation digital communications tools, 5 farms with most advanced websites and explicit social media presence were selected from the sample. In addition, 3 most prominent Latvian NGOs operating in organic farming sector were selected for detailed examination of digital communications strategies. Websites and social media tools used by these farms and NGOs were compared with similar farms and NGOs from the UK (3 farms and 3 NGOs), Ireland ( 3 farms and 2 NGOs), France (2 farms and 2 NGOs), Canada ( 3 farms and 2 NGOs) and the US (3 farms and 3 NGOs). The findings were summarized in a table that included the following parameters: range of digital tools used, frequency of content publication, quality and diversity of the content were considered. The number of followers on social media was not considered in this comparative analysis, as countries differ significantly in terms of population. Comparative analysis was conducted. Each organization was scored for each criterion on a Likert's 5-point scale. For range of digital tools, the following scale was used: very limited - less than 3 tools, limited - from 3 to 4 , broad from 4 to 6 to very broad -6 and more. For quality: very low - mainly text with limited number of low-resolution images, low - mainly text with acceptable quality images, medium - well balanced content with high quality images, high high quality content with clear layout and some extent of interactivity, very high - content rich in high quality features and often highly interactive. For diversity: very limited - content very homogenous, unlikely to attract visitor interest (heavy reliance on long text), limited - few types of content used (predominantly text with some sort of visual content), medium - good mix of diverse content and style in text and images, high - in addition to good mix of text and images limited use of video and/or audio content, very high - well balanced mix of diverse types of content including rich collection of video and/or audio materials. For frequency: very rare - less than once in 3 months, rare - once in 3 month to once in 2 month, medium frequent - once a month to once in two weeks, frequent - at least once a week, very frequent - at least two times a week. Farms and NGOs were evaluated separately. The farms and NGOs were ranked based sum of scales for each criterion. In addition to that, qualitative comparative analysis was conducted.

Studies on e-commerce in organic farming sector are rare, and the author is not aware of any study that has undertaken comparative analysis of digital communications usage within the organic farming sector between several countries. To the author's best knowledge no directly comparable studies have been conducted so far; therefore, findings of this study are novel.

\section{Results and discussion}

Results of thepresent study suggest that just $16 \%$ of Latvian organic farmers have websites. Moreover, from those farms with websites only about $2 / 3$ include e-stores. Other farms used websites for attracting tourists. Social media presence was also relatively low with only $12 \%$ of organic farms present on social media platforms. Majority of farms $(\sim 90 \%)$ that were present on social media used their landing pages for advertising purposes. Interestingly, only $4 / 5$ of those farms that have web-stores and were also present on social media, explicitly used social media pages to offer ordering their products from their web-stores. Remaining $1 / 5$ of such farms used social media pages for engagement with their potential customers and brand-building. Most popular social media channels were Facebook, LinkedIn and Draugiem.lv. Most farms (80\%) that had websites were present on Facebook, too. LinkedIn was the second most popular with $60 \%$ of those farms that had websites also had a page on LinkedIn. 
Draugiem.lv was more popular among farms that did not have websites, with only $30 \%$ of those present on this platform having a website, too.

Interesting patterns were revealed, when considering geographical location and product category of the organic farms. Presence of the livestock/dairy farms on the internet was much weaker than of other categories with only $1 / 5$ of farms that had some sort of presence on the internet being of the livestock/dairy category. It is important to note that almost $90 \%$ of livestock/dairy farms that had their own websites used them for attracting tourists. Interestingly, internet presence and availability of a webstore was particularly popular among organic farms that were engaged in beekeeping. It is also, important to note that $80 \%$ of the farms engaged in beekeeping that had websites also had web-stores offering to order honey online. This category represented almost $2 / 5$ of the farms that were present on the internet. Other $2 / 5$ were represented by growers. In terms of geographical location, the overall trend suggests that remotely located farms were reluctant to utilise digital tools, with only $25 \%$ of those farms that had some sort of the internet presence located further than $50 \mathrm{~km}$ from cities.

These findings indicate that majority organic farms in Latvia do not harness the power of ecommerce. Failure to adapt digital tools within organic farming industry may indicate that organic farmers may be losing out to conventional farms due to underused opportunities to access the market. Generally, reluctance to use digital tools among organic farmers is indeed surprising, as Latvia has very good internet penetration and coverage. There may be several possible reasons for such reluctance, including lack of knowledge and skills in the internet commerce or relatively high costs associated with building and running an internet shop. Also, lack of time may be between the reasons of underuse of ecommerce in organic industry in Latvia.

Comparative analysis of communications tools revealed that Latvian farmers and NGOs operating in the farming sector have some scope for further development. In terms of clarity of the key message conveyed by communications on websites Latvian farmers and NGOs were found to be superior to French and Irish organizations, and at the same level with the British, American and Canadian counterparts. However, in terms of range of digital tools used, frequency of content publication, quality and diversity of the content, Latvian farms and NGOs were found to lag behind foreign farmers and NGOs, respectively. The findings are outlined in Table 1.

Table 1

Comparison of digital communication activities among organic farmers and NGOs operating in organic farming sector across multiple counties

\begin{tabular}{|c|c|c|c|c|}
\hline Country & $\begin{array}{c}\text { Range of } \\
\text { digital tools }\end{array}$ & $\begin{array}{c}\text { Frequency of } \\
\text { content } \\
\text { publication }\end{array}$ & $\begin{array}{c}\text { Quality of } \\
\text { content }\end{array}$ & $\begin{array}{c}\text { Diversity of } \\
\text { content }\end{array}$ \\
\hline \multicolumn{5}{|c|}{ Farms } \\
\hline Latvia & limited & rare & high & limited \\
\hline The UK & very broad & very frequent & very high & very high \\
\hline Ireland & broad & very frequent & high & high \\
\hline France & broad & frequent & high & high \\
\hline Canada & very broad & very frequent & very high & very high \\
\hline The USA & very broad & very frequent & very high & very high \\
\hline \multicolumn{5}{|c|}{$N G O s$} \\
\hline Latvia & broad & medium & high & medium \\
\hline The UK & very broad & very frequent & very high & high \\
\hline Ireland & very broad & very frequent & very high & very high \\
\hline France & very broad & frequent & very high & high \\
\hline Canada & very broad & very frequent & very high & very high \\
\hline The USA & very broad & very frequent & very high & very high \\
\hline
\end{tabular}

As follows from the table, NGOs operating in organic farming sector generally outperform farms in terms of range and frequency of communications, as well as in terms of quality and diversity of the digital content. Considering the range of tools, it is important to note that Latvian farmers tend not to use video content and use a very limited photographical content in general. At the same time, British, 
Canadian and American farmers heavily use high quality photo and video materials, which are usually shared through YouTube and Instagram. French and Irish farms tend to share graphical and video content and share it through social media. However, in these countries the frequency, quality and diversity of the content tend to be lower than of the British, American and Canadian ones. These findings indicate that Latvian organic farms have a great scope for enhancing their digital communications strategies. Following examples of western colleagues, Latvian farms could harness unprecedented opportunities of developing and sharing video and photographical content. This could greatly reinforce effectiveness of marketing activities undertaken by organic Latvian farmers. Indeed, a recent study by Sokolova and Keff [11] suggests that YouTube and Instagram are among the most influential social media platforms, greatly affecting consumer buying decision making. In general, visual and dynamic content tends to be more engaging than the static textual content [12], this is particularly relevant when considering food industry, where the customer wants to see the product. It is also important to note that Latvian organic farmers tend to share content on their social media pages relatively rare (for most cases in our sample once in 3 month), while western farms were found to produce digital content much more frequently (from once in 2 weeks to once a month). It is well established that communication frequency is interlinked with its effectiveness [13]. Thus, it appears highly likely that, if Latvian organic farmers increased the frequency of content sharing, they could greatly benefit from consumer engagement, which, in turn, would contribute to sales.

Considering NGOs operating in organic farming industry, in general both Latvian and foreign organizations tend to be more proactive in use of digital communication tools than the farms. However, the scope still remains for Latvian NGOs to enhance digital marketing strategies. In the first place, range of digital tools and content diversity tends to be lower than in foreign NGOs. Similar to the situation with farms, Latvian NGOs rarely use such digital platforms as YouTube and Instagram and tend to produce small amount of photographical and video content. Thus, it seems apparent that the industry would benefit from more intensive usage of visual content.

Overall, the above findings suggest that e-commerce and digital communications in Latvian organic farming industry needs further development. Digital tools need to be promoted among Latvian organic farms and NGOs operating in the industry. National scale uptake of e-commerce and digital communications tools could be ensured by application of the adaptive management approach [14]. This approach would require involvement of multiple stakeholders and funding tools. These would include governmental support, professional organizations, such as LAD (The Rural Support Service), LAOCC (Latvian Agricultural Organization Cooperation Council), Latvian Rural Advisory and Training Centre, and regional Farmers' Parliaments, as well as prominent NGOs operating in the industry. Funding could be secured through European financial tools. Given the fact that one of the possible reasons for underuse of digital communications within the industry is most likely lack of knowledge and skills, it is essential to organize training programmes. Organizing training for representatives of Latvian organic farming industry could have significant benefits for Latvian economy and the environment, as it would increase competitiveness of the sector, and therefore merits investment [15].

Training alone may not result in wide uptake of digital communication tools among Latvian organic farms. Thus, another aspect of adaptive management - establishment of collaborative governance may be essential [16]. Here, collaboration between farmers, NGOs, and private sector is most likely to yield great success. Given the fact that low adaptation of e-commerce and digital tools among farmers may be due to lack of financial resources, time or human resources such collaborations could deliver essential support to farmers. Indeed, regularly producing high quality video and photographical content may be particularly time and labour intensive. At the same time, NGOs usually are more focused on communications activities and engage a large number of volunteers, thereby having more time and human resources, as well as expertise in digital communications. These resources may be harnessed by farmers, through collaboration with such organizations. Furthermore, collaboration between farmers may result in improved economies of scale, thereby allowing optimization of human resources and costs essential for successful e-commerce and digital marketing [17]. Although collaboration between competing farms within organic farming industry may be problematic, it is still possible to collaborate for the farms within organic clusters offering different types of products. For instance, a dairy farm could collaborate with growers and/or with beekeepers on building a common e-commerce platform. 
Considering collaboration with the private sector and academia with organic farming industry, a great scope for information and communications technology engineering exists here. Involvement of software engineers would be essential in order to develop optimal web-based e-commerce solutions for Latvian organic farmers. In line with the UN [6] recommendations, e-commerce and digital marketing should be a part of overall e-agriculture strategy (Figure 1).

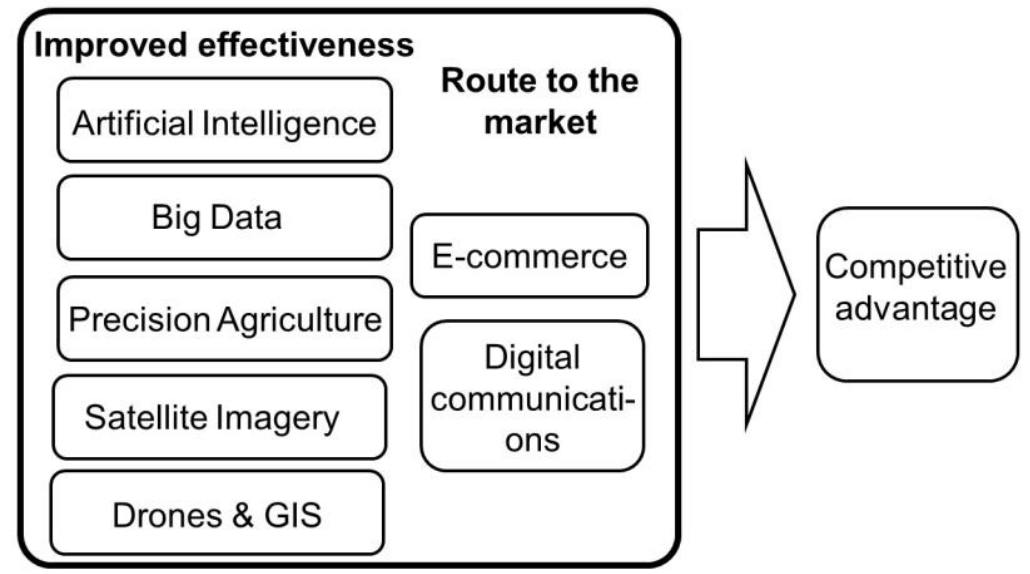

Fig. 1. Potential contribution of e-agriculture tools to competitive advantage of organic farming sector

E-agriculture in turn encompasses application of and integration of multiple digital technologies, such as Artificial Intelligence, Big Data, precision agriculture, Satellite imagery, GIS and application of drones, as well as e-commerce and digital communications tools that could benefit farms and increase their competitive advantage through application of these latest digital technologies. While the main goal of e-commerce and digital communications is to provide a route to the market for organic products, other technologies can improve effectiveness, especially cost and labour effectiveness, of organic farming industry in general. Resulting enhancement of competitive advantage could result in prosperity of the organic sector not only at a national scale, but also in international markets. So, engineers, software developers and academics could collaborate with farms on projects that could develop a holistic system of e-agriculture for organic farming in Latvia. In order to achieve wide uptake of e-agriculture in Latvia, the system should be user friendly and cost effective. This is indeed a challenging task; however, it is worth the effort and investment, because increased competitiveness of organic farming industry is likely to positively contribute to Latvian natural environment and economy, thereby successfully achieving the UN Sustainable development Goals [18].

\section{Conclusions}

The aim of present study was to identify whether organic farmers in Latvia utilise digital communications tools and whether there is a scope for improvement in this area. It was found that a very tiny proportion (less than 20\%) of organic farms in Latvia uses digital tools for the purposes of ecommerce and marketing communications. This finding indicates that representatives of organic farming industry in Latvia may be losing out to larger competitors from conventional farming industry and foreign competitors due to underuse of modern routs to the market. It was also found that in comparison to Western European, American and Canadian organic farms and NGOs operating in the industry, Latvian farms and NGOs utilise narrower range of digital communications tools, post online less frequently and use less diverse digital content. This indicates that there is a scope for improvement in digital communications area for both Latvian organic farms and NGOs. It is particularly important to increase usage of video and graphical content, which is particularly common among western organizations operating within the organic farming sector. Usage of visual content is known to be highly engaging and effective in affecting customer behaviour. In addition to that, it is essential to ensure that the content is produced and published more frequently and at a broader range of social media platforms that should include YouTube and Instagram in the first place.

Ensuring widespread application of e-commerce and digital communications tools within organic farming industry in Latvia is essential for achieving improvement of competitive advantage of the 
industry. This is an ambitious gaol, but it is worth the effort, as flourishing of organic farming is likely to have significant positive contribution to Latvian ecology and economy. In order to promote application of e-commerce among Latvian organic farmers and improvement of digital communications effectiveness, it is recommended to apply adaptive management approaches based on collaboration between multiple stakeholders. Furthermore, to reduce the cost, time and labour burden on farmers, it is essential to promote collaborative governance, developing strong links between farms, NGOs, representatives of private and academic sectors. In order to ensure maximal effectiveness of e-commerce and digital tool communications, it is also necessary to integrate it into a border national e-agriculture strategy. Here a contribution from engineers and academics could result in development of effective integrated and user-friendly solutions, which could make Latvian organic farming sector highly competitive both within the Latvian market and in international markets.

\section{References}

[1] The UN Global Biodiversity Outlook 5 Secretariat of the Convention on Biological Diversity. Montreal, 2020. $211 \mathrm{p}$.

[2] Donald P.F., Green R.E., Heath, M.F. Agricultural Intensification and the Collapse of Europe's Farmland Bird Populations. Proceedings: Biological Sciences, vol. 268(1462), 2001, pp. 25-29.

[3] Poppy G.M., Chiotha S., Eigenbrod F., Harvey C.A., Honzák M., Hudson M.D., Jarvis A., Madise N.J., Schreckenberg K., Shackleton C.M., Villa F., Dawson, T.P. Food security in a perfect storm: using the ecosystem services framework to increase understanding. Philosophical Transactions: Biological Sciences, vol. 369(1639), 2014, pp. 1-13.

[4] EC. Our life insurance, our natural capital: an EU biodiversity strategy to 2020. Brussels, EC, 2011, $17 \mathrm{p}$.

[5] Agence Bio. "Organic Farming and Market in the EU". [online] [01.03.2021]. Available at: https://www.agencebio.org/wp-content/uploads/2020/04/Organic_farming_market_EU_2019.pdf

[6] FAO. E-agriculture in action, 2017. [online] [25.02.2021]. Available at: http://www.fao.org/3/ai6972e.pdf

[7] Eurostat. "Organic Farming". [online] [20.02.2021]. Available at: https://ec.europa.eu/eurostat/statistics-explained/index.php/Organic_farming_statistics

[8] Sulonen K., Kotillainen S. Lessor's Status in Land Consolidation in Europe - Reports From Cyprus, Finland, France, Germany, the Netherlands, Latvia and Estonia. Baltic Journal of Real Estate Economics and Construction Management, vol. 3(1), 2016, pp. 56-71.

[9] RAND Corporation. A Million Random Digits with 100,000 Normal Deviates. Free Press, Santa Monica, Canada, 2000, 23 p.

[10]Latvian Agricultural Data Centre. [online] [21.01.2021]. Available at: https://www.ldc.gov.lv/lv/statistika/biologiska_lauksaimnieciba/

[11] Sokolova K, Keff H. Instagram and YouTube bloggers promote it, why should I buy? How credibility and parasocial interaction influence purchase intentions. Journal of Retailing and Consumer Services, vol. 53, 2020, DOI: 10.1016/j.jretconser.2019.01.011

[12] Gretzel U. The visual turn in Social Media marketing. TOURISMOS, vol. 12(3), 2017, pp. 1-18.

[13] Burton J.L., Gollins J., McNeely L.E., Walls D.M. Revisiting the Relationship between Ad Frequency and Purchase Intentions. Journal of Advertising Research, vol. 59(127-39), DOI https://doi.org/10.2501/JAR-2018-031

[14]Lin, B.B. Resilience in Agriculture through Crop Diversification: Adaptive Management for Environmental Change. BioScience, vol. 61(3), 2011, pp. 183-193.

[15] Darch H., Lucas T. Training as an e-commerce enabler. Journal of workplace Learning, vol. 14(4), pp. 148-155.

[16] Kallis G., Kiparsky M., Norgaard R. Collaborative governance and adaptive management: Lessons from California's CALFED Water Program. Environmental Science \& Policy, vol. 12(6), 2009, pp. 632-643.

[17] Holmes L. et al. Innovating public engagement and patient involvement through strategic collaboration and practice. Research Involvement and Engagement, vol. 5, 2019, pp. 1-12.

[18] The UN. "Sustainable Development Goals". [online] [25.02.2021]. Available at: https://www.un.org/sustainabledevelopment/sustainable-development-goals/ 